\title{
Construction of an Early Risk Warning Model of Organizational Resilience: An Empirical Study Based on Samples of R\&D Teams
}

\author{
Si-hua Chen \\ School of Information Technology, Jiangxi University of Finance and Economics, No. 169, East Shuanggang Road, \\ Changbei, Nanchang, Jiangxi 330013, China \\ Correspondence should be addressed to Si-hua Chen; doriancsh@foxmail.com
}

Received 30 November 2015; Accepted 3 May 2016

Academic Editor: Lu Zhen

Copyright (C) 2016 Si-hua Chen. This is an open access article distributed under the Creative Commons Attribution License, which permits unrestricted use, distribution, and reproduction in any medium, provided the original work is properly cited.

Facing fierce competition, it is critical for organizations to keep advantages either actively or passively. Organizational resilience is the ability of an organization to anticipate, prepare for, respond to, and adapt to incremental change and sudden disruptions in order to survive and prosper. It is of particular importance for enterprises to apprehend the intensity of organizational resilience and thereby judge their abilities to withstand pressure. By conducting an exploratory factor analysis and a confirmatory factor analysis, this paper clarifies a five-factor model for organizational resilience of R\&D teams. Moreover, based on it, this paper applies fuzzy integrated evaluation method to build an early risk warning model for organizational resilience of R\&D teams. The application of the model to a company shows that the model can adequately evaluate the intensity of organizational resilience of R\&D teams. The results are also supposed to contribute to applied early risk warning theory.

\section{Introduction}

The market complexity and competition intensity put forward higher requirements for enterprises. It is quite challenging for enterprises to pursue long-term success in the current intense competitive environment. A strategy enterprises can take is to achieve consecutive transient advantages by continuous innovations whereas organizational consistency and stability may damage their abilities to transform from one advantage to another. Rigidity can easily result in higher cost for enterprises when they adjust business strategies and thereby prevent enterprises from changing and weaken their abilities to tackle the changes. As a result, enterprises have to explore a series of resilience abilities, which are mainly derived from a wide range of key resources, the organizational structure, the diversified culture, and the leadership ability. Under this background, the concept of organizational resilience is proposed, which brings brand new perspective for strategic management. Organizational resilience emphasizes increasing resilience of enterprises, reducing the cost of switching strategies, and improving enterprises ability to respond to environmental dynamics. Sutcliffe and Vogus held the view that the resilient organizations can actively adjust in hard conditions [1]. Once they have conquered the severe challenges, the resilient enterprises can develop better. It is well recognized that the studies on organizational resilience provide train of thought for the high growth of enterprises in dynamic environment.

\section{Literature Review}

In terms of the definition of organizational resilience, generally there are two different views. The first view regards organizational resilience as simply an ability to rebound from unexpected, stressful, adverse situations and to pick up where they left off [2-5]. This point of view is similar to the physical definition of elasticity, namely, the ability of an object to recover to its original shape after deformation when it is subjected to extrusion. Scholars with this view often focus on the intensity of organizational resilience, that is, to what extent the organization can be restored to its original state after being subjected to negative pressure. The second point of view deems the organizational resilience to be the ability of an organization to be restored to its original state and become even stronger under negative pressure [6-8]. 
This view understands organizational resilience as a property of creatures. Not like the physical substances, creatures are not passively subjected to external force and recover afterwards. They can vigorously adapt themselves and make selfadjustment. What is more, organizational resilience is closely related to resilience of individual person in an organization. Nevertheless, it is not the simple aggregation of individual resilience. Organizational resilience pertains to organizational structure and interactions of individuals in an organization [9]. Until now, many studies on organizational resilience are descriptive [10-12]. But basically they agreed that organizational resilience was the embodiment of individual organizational capability. It is argued that these organizational capabilities and routines, in turn, are derived from a combination of individual level knowledge, skills, abilities, and other attributes (KSAOs) that are systematically developed and integrated through a firm's human resource management system [13].

In the early times, scholars defined the structural dimensions of organizational resilience more from individual qualities perspective. They emphasized the basis and the internal embodiment of resilience. For example, based on motivation theories London divided organizational resilience into three dimensions: self-efficacy, risk bearing, and independence [14]. These studies from individual qualities perspective to study organizational resilience are of theoretical significance, which laid solid foundation for the later research. However, this perspective did no good to exploring the mechanism of resilience nor to designing the intervention plans [15]. The individual qualities perspective understands resilience as a stable quality [16] but it ignores the possibility of dynamic development. In addition, if we understand organizational resilience as individual quality, a possible deduction is that maybe a person does not possess such quality. Therefore, the attention shifted to individual behaviors in organizational resilience studies appears very essential. The organizational resilience related behaviors refer to some individual behaviors presented in an organization to show individuals' confidence or elimination of confusion [17]; Noe et al. designed 13 behavioral dimensions, such as "to establish and maintain friendship with individuals of different departments," "ask if there is a problem when others are having a difficulty," and "greet to others actively when seeing them" [18]. Some studies pointed out that the behavioral dimensions of resilience included decisional behaviors, behaviors to seek job and competition. This behavior-oriented dimension indicates that resilience should incorporate the idea of "dynamic development process" [19].

Fourie and Van Vuuren made a relatively comprehensive study. The factor structure of resilience they explored included 45 items and 4 second-order factors. And they are belief in oneself, disregard for traditional sources of career success, self-reliance, and receptivity to change [20]. In addition, based on the studies of London and Noe et al., Liu discussed a structure with 20 items and 5 factors. The five factors are general properties such as change and risk taking, adaptability, autonomy and network building, employability and active learning, and self-confidence [21]. These comprehensive studies integrated the cognitive dimension, the contextual dimension, and behavioral dimension [22]. For instance, in Fourie and Van Vuuren study, the belief in oneself belongs to cognitive dimension and disregard for traditional sources of career success and receptivity to change belong to emotional dimension; self-reliance belongs to behavioral dimension. In fact, cognition, emotion, and behavior are the three elements of altitude [23]. According to this view, organizational resilience is individual altitude to job. Based on previous studies, Obrist et al. proposed that it was of importance to interpret organizational resilience based on cognitive, emotional, and behavioral dimensions. This idea coincides with that of Cynthia [24].

Early risk warning is the warning on the possible risks. The risks can be detected in advance and warned about because the happening of any risk needs certain conditions and causes. The outbreak of risk is bound to experience a period of formation, generation, evolution, manifestation, and function. In other words, from risk-taking effect to producing substantial damage and causing being out of control it is a process. Therefore, as long as there is effective early risk warning, risks can be effectively detected and evaluated and then transferred, diversified, controlled, and managed. In this way we can stop the further development of risks or deviate them from the target before the outbreak of risks or before they are out of control [25]. Generally organizational resilience has a boundary. Once the pressure organizations withstand is beyond the boundary, organizations can hardly be restored to the former state and even be paralyzed. Therefore, building an early risk warning system of organizational resilience is of extreme importance. However, there are very few studies discussing this topic.

Based on analysis of samples, this paper tries to address this problem by establishing an early risk warning model for organizational resilience. Firstly this paper discusses the factor structure of organizational resilience. Based on it, by conducting hierarchical analysis and fuzzy integrated evaluation this paper builds an early risk warning model. And, by applying the model to a company, this paper tests the effectiveness of the model.

\section{Empirical Study on the Organizational Resilience of R\&D Teams}

$\mathrm{R} \& \mathrm{D}$ team is an interactive discussion group which is used to produce knowledge and assumptions [26]. As far as all kinds of teams with different purposes are concerned, the importance of $R \& D$ teams outperforms the rest because $\mathrm{R} \& \mathrm{D}$ teams are the main subjects for enterprises to create knowledge [27]. Recently "R\&D teams" gradually become very popular vocabulary for new product development. R\&D team refers to a group of people who are temporarily assembled and are responsible for executing or completing some R\&D programs. Mainly by knowledge creation activities this group contributes to the appreciation of knowledge capital for enterprises. And its final purpose is to exploit and apply new products and new services. In this paper, we define "team" as a group between departments and individuals and " $R \& D$ team" as a formal group formed by the R\&D personnel from the R\&D programs. 


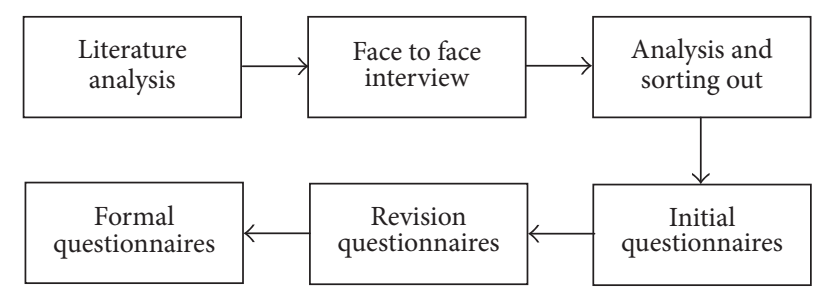

FIGURE 1: Questionnaire process.

Different from other teams, R\&D teams are knowledge teams. All the members are "knowledge workers." Generally speaking, knowledge workers are those people who have the ability to produce, create, expand, and apply knowledge and take knowledge work as professions [28-31]. Often knowledge capital of an enterprise is appreciated because of its knowledge work. Comparing with the traditional operational workers, knowledge workers more focus on and pursue the realization of their own values. They have relatively high independence and would like to take the challenging work with pleasure. But partly because of such features their turnover rate is high [32].

The above characteristics of R\&D teams differentiate them from other teams and departments in organizations. The operation of other teams or departments more depends on rigid institutions while, due to the particularity of its work nature, R\&D teams can not wholly depend on institution. R\&D teams should have flexibility. Therefore, the study on the resilience of $R \& D$ team is meaningful and has great practical significance. However, we can hardly see these studies currently.

3.1. Study Design. First of all, based on the analysis of literature on organizational resilience, we give definition to organizational resilience and decide the range of items. Then by interview and open questionnaire we collect all the items related to organizational resilience to form the questionnaires of organizational resilience. Finally, by applying questionnaires and multivariate statistical analysis, we explore the factor structure of organizational resilience. For the flow chart of questionnaire establishment see Figure 1.

3.2. Exploratory Factor Analysis. Based on both domestic and abroad studies on the dimensions of organizational resilience $[18,20,21]$, by literature review this paper designs open questionnaires and implements structural interview. According to Song, the structural interview objects need to be 10-15 homogenous members. Based on it [33], this paper chooses 15 $\mathrm{R} \& \mathrm{D}$ team leaders and $\mathrm{R} \& \mathrm{D}$ engineers to interview. The interview for each person lasts about 20 minutes. To guarantee the reliability and validity of these interviews, we mainly do two things: firstly, during the discussion, getting the permission of the interviewees, we record the important talks, points of view, and terms; secondly we sort out the notes and recording. We take notes where there is a question and if it is necessary, we pay a return visit to the interviewees by telephone. By content analysis, this paper sorts out the initial statements and deletes the statements of organizational resilience with semantic ambiguity. Then we make preliminary classification of the remaining statements and combine the statements with similar content and the statements only being expressed in different ways.

The objects of pretest are MBA members of Jiangxi University of Finance and Economics, who are the engineers in R\&D teams. Altogether we send 300 questionnaires and receive 203 questionnaires. SPSS 22.0 is used in processing and analyzing. Based on the factor analysis and item analysis, we find that the factor structure of the initial questionnaire is not clear and it has multiple loading items. So the initial questionnaires are not effective ones and need further revision. The principles for questionnaire revision are as follows: firstly, referring to the results of factor analysis, we choose the items with high communality and high factor loading and delete the items with low communality and low factor loading. Secondly, also referring to the results of factor analysis, we delete items with significant double loadings (the difference between the two biggest values of the factor loading is less than 0.2) and items whose maximum value of factor loading is less than 0.4. Then we adjust and delete the items with ambiguous meanings. Thirdly based on the scores of items we remove the items with low internal consistency reliability. After the revision, we choose 18 items from the initial questionnaire to form the formal questionnaire.

A factor analysis on the 18 items is conducted and the principal component analysis is adopted with varimax rotation. The statistical results confirm the presence of five unique factors of organizational resilience of $\mathrm{R} \& \mathrm{D}$ teams. The value of KMO is 0.907 and the value of Bartlett's ball test is 1245.034 with probability less than 0.001 . The total variance explanation rate is $62.010 \%$. Based on the understanding of each item, we define the five factors as shared vision, willingness to learn, adaptation ability, cooperative awareness, and work enthusiasm.

3.3. Confirmatory Factor Analysis. The results of the above survey show that organizational resilience has five dimensions with 18 items. But the factor structure only passes the exploratory factor analysis. Whether the theoretical model is better than the single dimensional model or other possible models still needs to be tested. In other words, we need to apply the confirmatory factor analysis to test the superiority of the theoretical model. Next we use the questionnaires of organizational resilience formed in the above survey to recollect the data to test the correctness of the questionnaires of organizational resilience.

In the confirmatory factor analysis, the survey objects are the $422 \mathrm{R} \& \mathrm{D}$ teams of 279 enterprises in 11 provinces in China. To ensure the independency of the data and to avoid possible interferences, this study differentiates the persons participating in CFA test and those in EFA test. Because we need to test the organizational resilience of $R \& D$ teams, we choose 2-3 members from each team [34]. The investigation time span is from January 2015 to June 2015. We send 1000 questionnaires and collect 509 questionnaires. The rate of effective questionnaires is $50.9 \%$. We use the organizational resilience questionnaires with 18 items and apply the Likert 5-point scale to evaluate each item; specific questionnaire was 


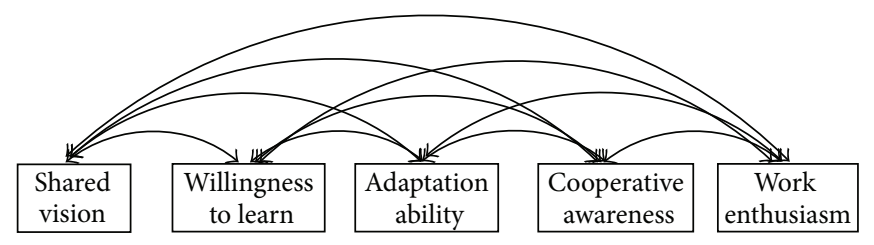

FIGURE 2: The hypothesized model of organizational resilience.

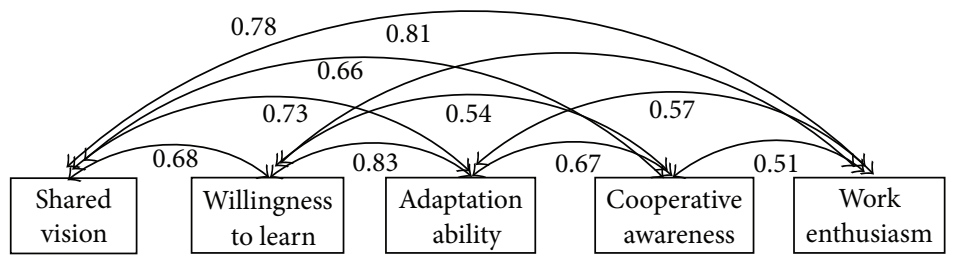

FIgURE 3: The structure model of organizational resilience.

TABLE 1: Fit indexes of organizational resilience model.

\begin{tabular}{ccccccc}
\hline Index & $\chi^{2}$ & GFI & AGFI & IFI & CFI & RMSEA \\
\hline Value & 270.68 & 0.92 & 0.90 & 0.93 & 0.92 & 0.05 \\
\hline
\end{tabular}

shown in the Appendix, in Supplementary Material available online at http://dx.doi.org/10.1155/2016/4602870. In this part, we hypothesize that the factor structure of organizational resilience is a five-factor model. See Figure 2.

We test the model by applying the structural equation model method. We fit the model with the observed values of a sample of 509 R\&D teams and get the factor structure of organizational resilience. See Figure 3.

To evaluate whether a model is acceptable or not, we mainly check the different fit indexes. For the main fit indexes see Table 1. The full name of each fit index is as follows: GFI: goodness-of-fit index; AGFI: adjusted goodness-of-fit index; IFI: incremental fit index; CFI: comparative fit index; RMSEA: Root Mean Square Error of Approximation.

From Table 1 we can find that all the fit indexes fall into the acceptable range, which indicates that the observed data well support the model. The exploratory factor analysis is confirmed.

3.4. Analysis Comparison with Other Possible Models. To further test the factor structure, this paper compares the fivefactor model with other competitive models. The competitive models include the single factor model, two-factor model, three-factor model, and four-factor model. There are 18 items in the questionnaires. Therefore, there is only one possibility for the single factor model; there are 153 possibilities for the two-factor model; there are 816 possibilities for threefactor model and 3060 possibilities for four-factor model. It is impossible for us to compare all of them. So the strategy we take is to find out the most reasonable model for each factor model and compare them. Based on the literature review in Section 2 [18-23], in the two-factor model, we combine shared vision and cooperative awareness as one factor. We combine willingness to learn, adaptation ability,
TABLE 2: Comparison of fit indexes of models.

\begin{tabular}{lcccccc}
\hline Index & $\chi^{2}$ & GFI & AGFI & IFI & CFI & RMSEA \\
\hline Five-factor model & 270.68 & 0.92 & 0.90 & 0.93 & 0.92 & 0.05 \\
Four-factor model & 159.36 & 0.88 & 0.78 & 0.82 & 0.67 & 0.161 \\
Three-factor model & 188.63 & 0.79 & 0.81 & 0.75 & 0.77 & 0.059 \\
Two-factor model & 213.42 & 0.57 & 0.62 & 0.75 & 0.89 & 0.231 \\
Single factor model & 230.34 & 0.93 & 0.88 & 0.89 & 0.90 & 0.025 \\
\hline
\end{tabular}

and work enthusiasm as another factor; in the three-factor model, we combine shared vision and cooperative awareness as one factor, willingness to learn and adaptation ability as the second factor, and work enthusiasm as the third factor; in the four-factor model, we combine shared vision and cooperative awareness as one factor and the three other factors remain as they are. We use AMOS 18.0 to analyze the five models and check their fitness. With the same data based on the questionnaire of Section 3.3, we can have the fitness of the five models.

CFI and IFI are the relative fit indexes; AGFI, GFI, and RMSEA are the absolute fit indexes. From Table 2 we can see that the RMSEA and GFI of single factor model are better than those of five-factor model. But the AGFI, IFI, and CFI of single factor model are all smaller than those of five-factor model. RMSEA indicates the gap between the theoretical model and the saturated model. Its value is smaller than 0.05 , which indicates that the model has very good fitness. A model can be accepted only when the values of GFI, AGFI, IFI, and CFI are bigger than 0.9. The AGFI and IFI of the single factor model are smaller than 0.9 ; the values of fit indicators of the two-factor model, three-factor model, and four-factor model are all unacceptable while all the fit indicators of the five-factor model can meet the requirements. The AGFI, GFI, IFI, and CFI of five-factor model are all bigger than 0.9 and RMSEA is 0.05 , which shows good fitness. Considering the fitness of these models, we deem the best structure to be the five-factor model. 


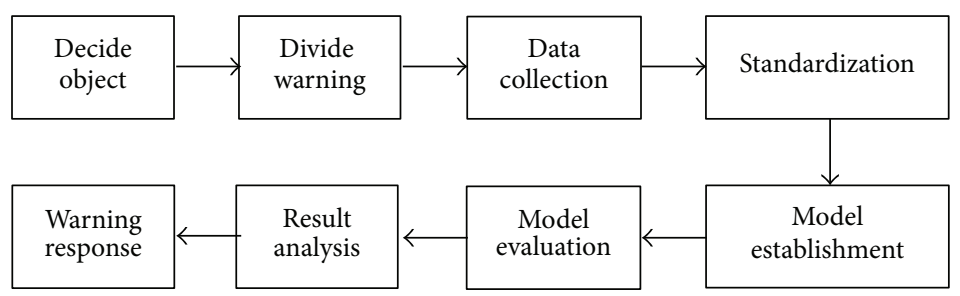

FIGURE 4: Steps to build the early risk warning model of risk.

TABLE 3: Reliability analysis of measurement variables.

\begin{tabular}{lcc}
\hline Variable & Item & Cronbach's alpha \\
\hline Shared vision & 4 & 0.798 \\
Willingness to learn & 4 & 0.805 \\
Adaptation ability & 3 & 0.817 \\
Cooperative awareness & 4 & 0.902 \\
Work enthusiasm & 3 & 0.893 \\
\hline
\end{tabular}

3.5. Reliability and Validity Analysis. In this paper, a test of internal consistency reliability using Cronbach's coefficient alphas was performed. As shown in Table 3, Cronbach's alpha coefficients fall between 0.798 and 0.902 , which are all bigger than 0.7. It shows that the questionnaires have high internal consistency reliability and are acceptable.

Validity refers to the effectiveness and correctness of questionnaires, that is, the extent to which the questionnaire can measure the characteristics of the construct. It is an important criterion to evaluate the quality of questionnaires. Generally it includes the content validity and construct validity. Content validity refers to the extent to which a measure represents all facets of a given construct. In terms of content validity, parts of the items come from the current papers, which are used by many scholars to measure similar variables. Other parts of the items are designed based on literature review. What is more, these questionnaires are further revised based on the interviews and pretest results. Therefore, the content of the questionnaires matches well the object and has good content validity.

Construct validity is used to test the degree to which a test measures what it claims. It mainly uses factor analysis to test the construct validity. The main indexes are value of KMO and value of the Bartlett ball test. The value of KMO is 0.6 , which indicates that construct validity is moderate. 0.7 indicates that the construct validity is good and 0.8 indicates it is very good. In terms of the value of the Bartlett ball test, the smaller the better. It performs well when $p<0.0001$. Table 4 shows the value of KMO and value of the Bartlett ball test.

From the analysis shown in Table 4, we can see that the value of $\mathrm{KMO}$ of each latent variable is bigger than 0.7 and the value of $p$ is 0 ; the Bartlett ball tests show concentration. All indicate that the construct validity is good. Considering both content validity and construct validity, we can draw the conclusion that the indicator system and the questionnaires of this paper have high validity.
TABLE 4: Validity analysis of measurement variables.

\begin{tabular}{lcccc}
\hline \multirow{2}{*}{ Variable } & \multirow{2}{*}{ KMO } & \multicolumn{3}{c}{ Bartlett } \\
& & Chi-square & DF & Sig \\
\hline Shared vision & 0.761 & 384.541 & 232 & 0.000 \\
Willingness to learn & 0.824 & 479.564 & 232 & 0.000 \\
Adaptation ability & 0.794 & 243.799 & 232 & 0.000 \\
Cooperative awareness & 0.857 & 461.139 & 232 & 0.000 \\
Work enthusiasm & 0.798 & 597.873 & 232 & 0.000 \\
\hline
\end{tabular}

\section{Construction of the Early Risk Warning Model of Organizational Resilience of R\&D Team}

4.1. Steps for Construction of Early Risk Warning Model. These are steps for enterprises to construct an early risk warning model: firstly we need to decide the objects and select an early risk warning indicator system guided by the early risk warning principles; secondly we divide the risk warning levels and the warning line; thirdly we collect the data and process the data and normalize the data; fourthly we construct the mathematical model and evaluate the model by empirical analysis; fifthly we analyze the results and judge the relationship between the results and the warning line and give early risk warning response. Please see Figure 4.

In this study, the object of the early risk warning model is organizational resilience. Based on the analysis of Section 3, the indicator system of the early risk warning model can be divided into 2 levels: the first level is the five factors of organizational resilience and the second level is the items of each factor. The risk warning levels can be divided into 5 levels and they are without warning, light warning, medium warning, heavy warning, and dangerous warning.

This paper uses fuzzy integrated evaluation method [35] mainly due to the following reasons: firstly it is difficult to precisely quantify the evaluation of enterprise risk warning. There is ambiguity. Based on fuzzy sets and by using various indicators, the fuzzy integrated evaluation method can give comprehensive evaluation of the membership degree of the evaluated objects. By dividing the intervals, on the one hand it considers the levels of the objects and reflects the ambiguity of the evaluation standards. On the other hand, it takes the advantages of people's experiences, which makes the results more objective and adaptable to the reality. By combining both qualitative and quantitative factors, fuzzy integrated 
evaluation method improves the quality of evaluation and the reliability of results.

4.2. Determine the Weights. To reduce the randomness of judgment and increase the reliability of result, this paper adopts the fuzzy evaluation method which combines fuzzy set theory and analytical hierarchy process.

$U=\left(U_{1}, U_{2}, U_{3}, U_{4}, U_{5}\right)$, where $U_{i}$ denotes one dimension of organizational resilience. $Q=\left(q_{1}, q_{2}, \ldots, q_{13}\right)$, which are the criterion of the above five aspects. $V=\left(v_{1}, v_{2}, v_{3}, v_{4}, v_{5}\right)$, where $v_{1}, v_{2}, v_{3}, v_{4}, v_{5}$ respectively, denotes the "strong," "good," "general," "fairly weak," and "weak" comment of each criterion.

This paper adopts analytical hierarchy process method to decide the weights of indicators. Users of the AHP first decompose their decision problem into a hierarchy of more easily comprehended subproblems. Once the hierarchy is built, the decision makers will use their judgments about the elements' relative meaning and importance to evaluate these elements by comparing them to one another at a time. It is recognized to be practical, systematic, and concise [36].

Based on the analysis of Section 3, we establish priorities among the elements of the hierarchy by making a series of judgments based on pairwise comparisons of the elements. We can synthesize these judgments to yield a set of overall priorities for the hierarchy.

The priorities of criteria $U_{i}$ are $a_{1}, a_{2}, a_{3}, a_{4}, a_{5}$ and $A=$ $\left(a_{1}, a_{2}, a_{3}, a_{4}, a_{5}\right)$. The main steps are as follows:

(1) According to scaling theory, we construct pairwise comparison judgment matrix $A$ :

$$
A=\left(a_{i j}\right)_{n \times n}, \quad(i, j=1,2, \ldots, n) .
$$

(2) Normalize the columns of judgment matrix $A$ :

$$
a_{i j}^{\prime}=\frac{a_{i j}}{\sum_{k=1}^{n} a_{k j}}, \quad(i, j=1,2, \ldots, n) .
$$

(3) Calculate the sum of each row of judgment matrix $A w_{i}$ :

$$
w_{i}=\sum_{j=1}^{n} a_{i j}, \quad(i, j=1,2, \ldots, n) .
$$

(4) Normalizing $w_{i}$ we can get

$$
w_{i}^{\prime}=\frac{w_{i}}{\sum_{i=1}^{n} w_{i}} .
$$

(5) According to $A w=\lambda_{\max } w$, we can calculate the largest eigenvalue and its eigenvector.

(6) Consistency test: by calculating the consistency index C.I. $=\left(\lambda_{\max }-n\right) /(n-1)$, we can find the corresponding average random consistency index R.I.. Then we can calculate the consistency ratio C.R. = C.I./R.I.. When C.R. $<0.1$, we accept the result. Otherwise, we need to rectify matrix $A$ appropriately.
4.3. Establishment of Qualitative Indexes Membership. Although we can get definite comments on each criterion, the "boundary" is relatively ambiguous. Therefore, when calculating the membership degree of each criterion to the evaluation set, we need to grade each criterion based on specialist consultancy and questionnaire analysis. We can get the membership vector $R_{j}$ of criterion $q_{i}$ to evaluation set $V . R_{j}=\left(r_{j 1}, r_{j 2}, r_{j 3}, r_{j 4}, r_{j 5}\right), j=1,2, \ldots, 13, r_{j n}(n=$ $1,2,3,4,5)$, said that there is evaluation value $q_{i}$. And we have $r_{j i}=v_{j i} / \sum v_{j n} \cdot \sum v_{j n}=v_{j 1}+v_{j 2}+v_{j 3}+v_{j 4}+v_{j 5}$. We can get the evaluation membership matrix of the indicator of trust.

4.4. Comprehensive Evaluation. (1) Comprehensive evaluation vector of subgoals: suppose $B_{i}=w_{i} \oplus R_{i}(i=1,2$, $3,4,5)$, where $\oplus$ is the operator and its definition is $b_{i}=$ $\sum_{i=1}^{n} w_{i} r_{i j}$, where $b_{i}$ is the membership vector of each kind of organizational resilience. Normalizing $b_{i}$ we can get $B=$ $\left(B_{1}, B_{2}, B_{3}, B_{4}, B_{5}\right)^{T}$.

(2) Final evaluation vector of the overall goal: suppose $C=A \oplus B$. We add the first two items together. If the sum is bigger than 0.5 (i.e., the percentage of "strong" and "good" is bigger than $50 \%$ ), it indicates that the organizational resilience is strong. The more approaching 1 the sum of first two items, the stronger the organizational resilience.

\section{Case Analysis}

This paper combines both empirical study and case study to systematically study the factors which influence sustainable innovation. The main conclusions are as follows.

Jiangling Motors Co., Ltd. (JMC in abbreviation hereinafter), a key player in China automotive industry with commercial vehicle as its core competitiveness, has been ranked as one of China Top 100 Listed Companies for consecutive years. In 2014, JMC hit record highs in its business indexes with sales revenue reaching 25.5 billion RMB and volume over 276,000 units. JMC, who has established international standards that complied with operating systems and mechanisms that integrate R\&D, logistics, MS\&S, and financing supports, has been regarded as a model of successful Sinoforeign cooperation. The company has set up a strong marketing network throughout China. Its products include Transit commercial vehicle, Kaiyun light truck, Baodian pickup, and Yusheng SUV, which have become models of fuel saving, practicality, and environment friendliness. In recent years, JMC has been investing heavily in new product development to enrich its product line. We analyze and evaluate the organizational resilience of R\&D team of JMC company based on the method of Section 4. The specific steps are as follows.

5.1. Calculate Weights. We apply analytical hierarchical process method to decide weights. Based on the pairwise comparison of importance of criteria, we use 1-9 scaling method to get $A_{i}$ and they are

$$
\begin{aligned}
& A_{1}=(0.341,0.572,0.195,0.432,0.273), \\
& A_{2}=(0.438,0.581,0.249,0.621,0.275),
\end{aligned}
$$




$$
\begin{aligned}
& A_{3}=(0.417,0.359,0.721,0.346,0.512), \\
& A_{4}=(0.438,0.519,0.434,0.419,0.351), \\
& A_{5}=(0.523,0.475,0.354,0.464,0.765) .
\end{aligned}
$$

Normalizing them, we can get $w_{i}$. We calculate the largest eigenvalue and its eigenvector and make consistency test. Then we can get C.R. $=$ C.I. $/$ R.I. $=0.043<0.1$. It indicates that the consistency of judgment matrix is acceptable.

5.2. Establishment of Membership Matrix of Fuzzy Evaluation. Based on the above analysis, we select a group of 33 experts. They mainly come from two sources: 17 of them are leaders of departments and senior engineers of enterprises and 16 of them are college professors in human resource management. The alternative answers include "extreme important, very important, important, a little important, and not important" and we give each of them from 5 to 1 , respectively. We send them the questionnaires by email and make sure they do not know each other's answer. Then we can get the membership matrix:

$$
\begin{aligned}
& R_{1}=\left(\begin{array}{lllll}
0.456 & 0.812 & 0.654 & 0.142 & 0.461 \\
0.451 & 0.641 & 0.247 & 0.541 & 0.622 \\
0.751 & 0.712 & 0.574 & 0.341 & 0.346 \\
0.235 & 0.632 & 0.341 & 0.723 & 0.348 \\
0.432 & 0.543 & 0.355 & 0.541 & 0.156
\end{array}\right), \\
& R_{2}=\left(\begin{array}{lllll}
0.634 & 0.247 & 0.541 & 0.346 & 0.316 \\
0.453 & 0.621 & 0.421 & 0.261 & 0.423 \\
0.431 & 0.354 & 0.354 & 0.156 & 0.761 \\
0.312 & 0.317 & 0.641 & 0.341 & 0.345 \\
0.231 & 0.394 & 0.521 & 0.141 & 0.432
\end{array}\right) \text {, } \\
& R_{3}=\left(\begin{array}{lllll}
0.345 & 0.384 & 0.347 & 0.512 & 0.712 \\
0.311 & 0.371 & 0.621 & 0.315 & 0.731 \\
0.421 & 0.381 & 0.274 & 0.311 & 0.623 \\
0.235 & 0.267 & 0.646 & 0.328 & 0.512 \\
0.512 & 0.461 & 0.346 & 0.612 & 0.641
\end{array}\right) \text {, } \\
& R_{4}=\left(\begin{array}{lllll}
0.421 & 0.379 & 0.513 & 0.812 & 0.385 \\
0.356 & 0.812 & 0.346 & 0.346 & 0.541 \\
0.841 & 0.644 & 0.311 & 0.461 & 0.197 \\
0.345 & 0.547 & 0.345 & 0.856 & 0.634 \\
0.314 & 0.284 & 0.346 & 0.654 & 0.461
\end{array}\right) \text {, } \\
& R_{5}=\left(\begin{array}{lllll}
0.765 & 0.698 & 0.611 & 0.341 & 0.341 \\
0.395 & 0.541 & 0.851 & 0.206 & 0.261 \\
0.584 & 0.621 & 0.511 & 0.509 & 0.345 \\
0.347 & 0.574 & 0.341 & 0.451 & 0.433 \\
0.614 & 0.354 & 0.317 & 0.394 & 0.542
\end{array}\right) \text {. }
\end{aligned}
$$

5.3. Calculating the Comprehensive Evaluation Vector of Each Subgoal. From $B_{i}=w_{i} \oplus R_{i}$, we have

$$
\begin{aligned}
B_{1}= & \left(\begin{array}{l}
0.201 \\
0.210 \\
0.177 \\
0.207 \\
0.207
\end{array}\right) \\
& \left(\begin{array}{lllll}
0.456 & 0.812 & 0.654 & 0.142 & 0.461 \\
0.451 & 0.641 & 0.247 & 0.541 & 0.622 \\
0.751 & 0.712 & 0.574 & 0.341 & 0.346 \\
0.235 & 0.632 & 0.341 & 0.723 & 0.348 \\
0.432 & 0.543 & 0.355 & 0.541 & 0.156
\end{array}\right)
\end{aligned}
$$$$
B_{1}=\left(\begin{array}{lllll}
0.457 & 0.667 & 0.429 & 0.646 & 0.389
\end{array}\right) \text {, }
$$$$
B_{2}=\left(\begin{array}{l}
0.272 \\
0.245 \\
0.133 \\
0.215 \\
0.165
\end{array}\right)^{T}
$$$$
\oplus\left(\begin{array}{lllll}
0.634 & 0.247 & 0.541 & 0.346 & 0.316 \\
0.453 & 0.621 & 0.421 & 0.261 & 0.423 \\
0.431 & 0.354 & 0.354 & 0.156 & 0.761 \\
0.312 & 0.317 & 0.641 & 0.341 & 0.345 \\
0.231 & 0.394 & 0.521 & 0.141 & 0.432
\end{array}\right),
$$$$
B_{2}=\left(\begin{array}{lllll}
0.446 & 0.400 & 0.521 & 0.275 & 0.436
\end{array}\right),
$$$$
B_{3}=\left(\begin{array}{l}
0.127 \\
0.132 \\
0.337 \\
0.227 \\
0.155
\end{array}\right)^{T}
$$$$
\oplus\left(\begin{array}{lllll}
0.345 & 0.384 & 0.347 & 0.512 & 0.712 \\
0.311 & 0.371 & 0.621 & 0.315 & 0.731 \\
0.421 & 0.381 & 0.274 & 0.311 & 0.623 \\
0.235 & 0.267 & 0.646 & 0.328 & 0.512 \\
0.512 & 0.461 & 0.346 & 0.612 & 0.641
\end{array}\right),
$$$$
B_{3}=\left(\begin{array}{lllll}
0.359 & 0.358 & 0.419 & 0.381 & 0.612
\end{array}\right) \text {, }
$$

$$
B_{4}=\left(\begin{array}{l}
0.241 \\
0.282 \\
0.138 \\
0.187 \\
0.174
\end{array}\right)^{T}
$$


$\oplus\left(\begin{array}{lllll}0.421 & 0.379 & 0.513 & 0.812 & 0.385 \\ 0.356 & 0.812 & 0.346 & 0.346 & 0.541 \\ 0.841 & 0.644 & 0.311 & 0.461 & 0.197 \\ 0.345 & 0.547 & 0.345 & 0.856 & 0.634 \\ 0.314 & 0.284 & 0.346 & 0.654 & 0.461\end{array}\right)$

$B_{4}=\left(\begin{array}{lllll}0.437 & 0.561 & 0.389 & 0.631 & 0.471\end{array}\right)$,

$B_{5}=\left(\begin{array}{l}0.159 \\ 0.131 \\ 0.215 \\ 0.164 \\ 0.300\end{array}\right)^{T}$

$\oplus\left(\begin{array}{lllll}0.765 & 0.698 & 0.611 & 0.341 & 0.341 \\ 0.395 & 0.541 & 0.851 & 0.206 & 0.261 \\ 0.584 & 0.621 & 0.511 & 0.509 & 0.345 \\ 0.347 & 0.574 & 0.341 & 0.451 & 0.433 \\ 0.614 & 0.354 & 0.317 & 0.394 & 0.542\end{array}\right)$,

$B_{5}=\left(\begin{array}{lllll}0.540 & 0.516 & 0.470 & 0.383 & 0.396\end{array}\right)$.

Based on $B=\left(B_{1}, B_{2}, B_{3}, B_{4}, B_{5}\right)^{T}$, normalizing it and from $C=A \oplus B$, we have

$$
\begin{aligned}
C & =\left(\begin{array}{l}
0.195 \\
0.226 \\
0.176 \\
0.206 \\
0.196
\end{array}\right) \\
& \oplus\left(\begin{array}{lllll}
0.204 & 0.267 & 0.193 & 0.218 & 0.169 \\
0.199 & 0.160 & 0.234 & 0.129 & 0.189 \\
0.160 & 0.143 & 0.188 & 0.178 & 0.266 \\
0.195 & 0.224 & 0.175 & 0.296 & 0.204 \\
0.241 & 0.206 & 0.211 & 0.179 & 0.172
\end{array}\right) \\
C= & \left(\begin{array}{lllll}
0.302 & 0.200 & 0.201 & 0.149 & 0.148
\end{array}\right) .
\end{aligned}
$$

The sum of first two items of $C$ is 0.502 . The sum of first three items of $C$ is 0.703 . It indicates the light warning and shows the R\&D team has relatively high organizational resilience.

\section{Conclusions}

Based on the structural interviews, this paper explores and confirms the structural dimensions of organizational resilience. Based on it, this paper constructs an early risk warning model of organizational resilience and applies it to the R\&D team of JMC company. The conclusions are as follows.

(1) Based on literature review, face to face interviews, and open questionnaires, this paper applies the exploratory factor analysis method to discuss the factor structure of organizational resilience of $\mathrm{R} \& \mathrm{D}$ teams. The results show that the factor structure of organizational resilience of $R \& D$ teams includes five dimensions: shared vision, willingness to learn, adaptation ability, cooperative awareness, and work enthusiasm. Then this paper compares the five-factor model with other competitive models to further test the effectiveness of the five-factor model. The results show that the five-factor model is the best. What is more, the validity and reliability of the questionnaires of organizational resilience are proved to meet the requirements of psychometrics. The model is supported.

(2) Based on the factor structure of organizational resilience, this study constructs an early risk warning model of organizational resilience of R\&D teams. It divides the risk warning levels into five levels. By applying fuzzy integrated evaluation method and based on the five-factor structure, this paper constructs a hierarchical analysis structure model. By making a series of judgments based on pairwise comparisons of the elements, we can get the judgment matrix and thereby decide the weight of each factor of organizational resilience. Then, by using Delphi method, we can get the membership matrix. Lastly, by calculating the judgment matrix and membership matrix, we can know the risk warning level of organizational resilience of the R\&D team. We hope the result will provide references for the company decision.

(3) This study applies the early risk warning model to $\mathrm{R} \& \mathrm{D}$ team of JMC company. The results show that the team has relatively high organizational resilience. These results match the work performance, work experiences, and leaders' remarks on the team. It also matches the self-evaluation of members of the team. All these show that the method is operational and feasible.

\section{Competing Interests}

The author declares no competing interests. The author has no financial and personal relationships with other people or organizations that can inappropriately influence the work.

\section{Acknowledgments}

This work is supported by the NSFC (71361013, 71462009, 71273122, and 71463020); China Postdoctoral Science Foundation under Grant no. 2013M541867; Jiangxi Province Science Foundation of China under Grants nos. 20151BAB207059 and 20142BA217018; and China Scholarship Council Funding under Grant no. 201409805006.

\section{References}

[1] K. M. Sutcliffe and J. T. Vogus, "Organizing for resilience," in Positive Organizational Scholarship: Foundations of a New Discipline, pp. 94-110, 2003. 
[2] J. H. Gittell, K. Cameron, S. Lim, and V. Rivas, "Relationships, layoffs, and organizational resilience: airline industry responses to September 11," Journal of Applied Behavioral Science, vol. 42, no. 3, pp. 300-329, 2006.

[3] J. W. Rudolph and N. P. Repenning, "Disaster dynamics: understanding the role of quantity in organizational collapse," Administrative Science Quarterly, vol. 47, no. 1, pp. 1-30, 2002.

[4] J. E. Dutton, P. J. Frost, M. C. Worline, J. M. Lilius, and J. M. Kanov, "Leading in times of trauma," Harvard Business Review, vol. 80, no. 1, pp. 54-61, 2002.

[5] R. Balu, "How to bounce back from setbacks," Fast Company, vol. 45, pp. 148-156, 2001.

[6] K. E. Weick, "Enacted sense making in crisis situations," Journal of Management Studies, vol. 25, no. 4, pp. 305-317, 1988.

[7] D. L. Coutu, "How resilience works," Harvard Business Review, vol. 80, no. 5, pp. 46-55, 2002.

[8] S. F. Freeman, M. Maltz, and L. Hirschhorn, "The power of moral purpose: Sandler O'Neill \& partners in the aftermath of September 11th, 2001," Organization Development Journal, vol. 22, no. 4, pp. 69-82, 2004.

[9] F. P. Morgeson and D. A. Hofmann, "The structure and function of collective constructs: implications for multilevel research and theory development," Academy of Management Review, vol. 24, no. 2, pp. 249-265, 1999.

[10] J. F. I. Horne, "The coming of age of organizational resilience," Business Forum, vol. 22, no. 2-3, pp. 24-28, 1997.

[11] L. A. Mallak, "Measuring resilience in health care provider organizations," Health Manpower Management, vol. 24, no. 4-5, pp. 148-152, 1998.

[12] L. A. Mallak, "Putting organizational resilience to work," Industrial Management, vol. 40, no. 6, pp. 8-13, 1998.

[13] C. A. Lengnick-Hall, T. E. Beck, and M. L. Lengnick-Hall, "Developing a capacity for organizational resilience through strategic human resource management," Human Resource Management Review, vol. 21, no. 3, pp. 243-255, 2011.

[14] M. London, “Toward a theory of career motivation," Academy of Management Review, vol. 8, no. 4, pp. 620-630, 1983.

[15] Y. Xiao-nan and Z. Jian-xin, "Resilience: the psychological mechanism for recovery and growth," Advances in Psychological Science, vol. 5, no. 5, pp. 658-665, 2005.

[16] X. Ju-Zhe, S. Biao, and Z. Zhi-Hong, "The research on resilience : its evolution and direction," Psychological Science, vol. 31, no. 4, pp. 995-998, 2008.

[17] E. Grotberg, "Resilience for tomorrow," Trabajo presentado en la International Council of Psychologists Convention, Foz do Iguaçu, Brazil. Extraído de 2005, https://www.hitpages.com/ doc/6257244572221440/1.

[18] R. A. Noe, A. W. Noe, and J. A. Bachhuber, "An investigation of the correlates of career motivation," Journal of Vocational Behavior, vol. 37, no. 3, pp. 340-356, 1990.

[19] F. Luthans, J. B. Avey, R. Clapp-Smith, and W. Li, "More evidence on the value of Chinese workers' psychological capital: a potentially unlimited competitive resource?" The International Journal of Human Resource Management, vol. 19, no. 5, pp. 818$827,2008$.

[20] C. Fourie and L. J. Van Vuuren, "Defining and measuring career resilience," SA Journal of Industrial Psychology, vol. 24, no. 3, pp. 52-59, 1998.

[21] Y. C. Liu, Relationships between Career Resilience and Career Beliefs of Employees in Taiwan, Texas A\&M University, 2003.
[22] B. Obrist, C. Pfeiffer, and R. Henley, "Multi-layered social resilience: a new approach in mitigation research," Progress in Development Studies, vol. 10, no. 4, pp. 283-293, 2010.

[23] S. J. Breckler, "Empirical validation of affect, behavior, and cognition as distinct components of attitude," Journal of Personality \& Social Psychology, vol. 47, no. 6, pp. 1191-1205, 1984.

[24] C. A. Lietz and M. Strength, "Stories of successful reunification: a narrative study of family resilience in child welfare," Families in Society: The Journal of Contemporary Social Services, vol. 92, no. 2, pp. 203-210, 2011.

[25] X. Zhao and Z.-G. Xin, "Research review on models of enterprise risk forewarning management," Journal of Beijing University of Posts and Telecommunications (Social Sciences Edition), vol. 12, no. 1, pp. 93-97, 2010.

[26] E. F. Fern, "The use of focus groups for idea generation: the effects of group size, acquaintanceship, and moderator on response quantity and quality," Journal of Marketing Research, vol. 19, no. 1, pp. 1-13, 1982.

[27] S.-H. Chen and W. He, "Study on knowledge propagation in complex networks based on preferences, taking wechat as example," Abstract and Applied Analysis, vol. 2014, Article ID 543734, 11 pages, 2014.

[28] W. He, "An inventory controlled supply chain model based on improved BP neural network," Discrete Dynamics in Nature and Society, vol. 2013, Article ID 537675, 7 pages, 2013.

[29] S.-H. Chen, "A novel culture algorithm and it's application in knowledge integration," Information, vol. 15, no. 11 B, pp. $4847-$ 4853, 2012.

[30] W. He and S.-H. Chen, "Game analysis of determinants of stability of semiconductor modular production networks," Sustainability, vol. 6, no. 8, pp. 4772-4794, 2014.

[31] S.-H. Chen, "The influencing factors of enterprise sustainable innovation: an empirical study," Sustainability, vol. 8, no. 5, article 425, 17 pages, 2016.

[32] S.-H. Chen, "Empirical research on knowledge integration improving innovation ability of IT enterprise-based on structural equation model," Information, vol. 14, no. 3, pp. 753-758, 2011.

[33] G.-X. Song, "Study on construct and its dimensions of career resilience: based on Chinese indigenous culture," Economic Management, vol. 33, no. 11, pp. 184-193, 2011.

[34] J.-L. Ke, J.-M. Sun, J.-T. Shi, and Q.-X. Gu, "Empirical study on relationship between social capital of R\&D team and team potency," Management World, vol. 3, pp. 89-101, 2007.

[35] H. Shouzhong and G. Jianqin, "Fuzzy integrated evaluation and its application," Journal of China Textile University, vol. 21, no. 1, pp. 74-80, 1995.

[36] A. Jebreen and A. Husain, "Utility-based approach for determining the weights of participants in virtual organization," Applied Mathematical Sciences, vol. 6, no. 96, pp. 4773-4786, 2012. 


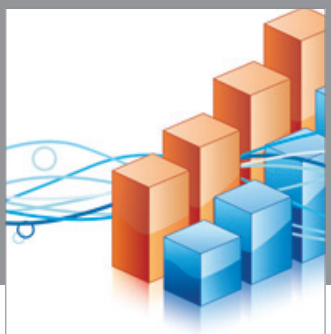

Advances in

Operations Research

vatem alat4

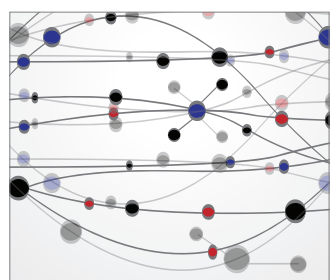

\section{The Scientific} World Journal
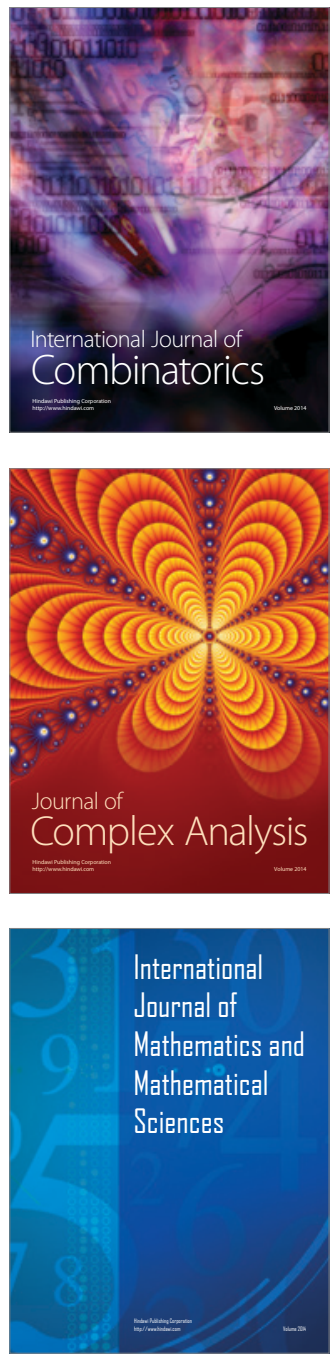
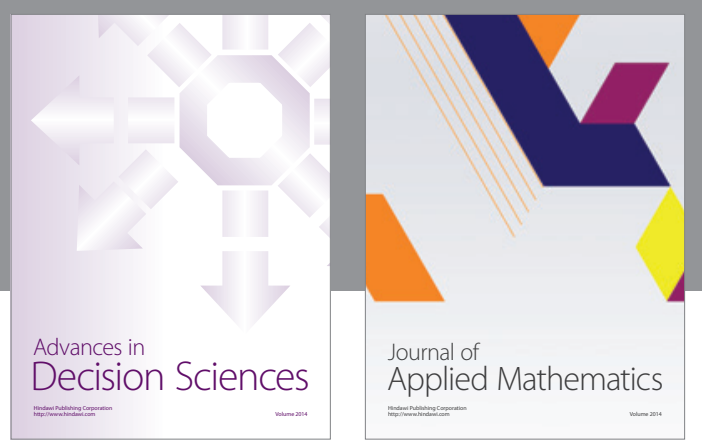

Algebra

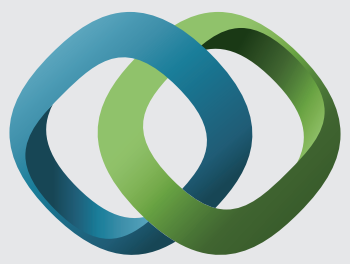

\section{Hindawi}

Submit your manuscripts at

http://www.hindawi.com
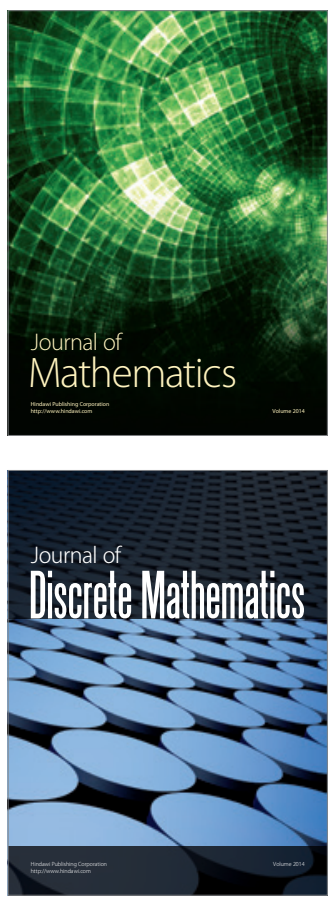

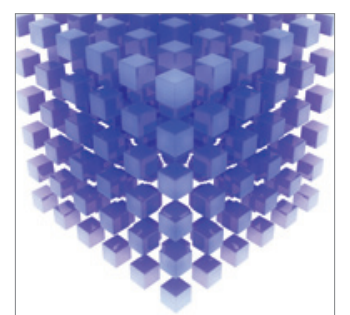

Mathematical Problems in Engineering
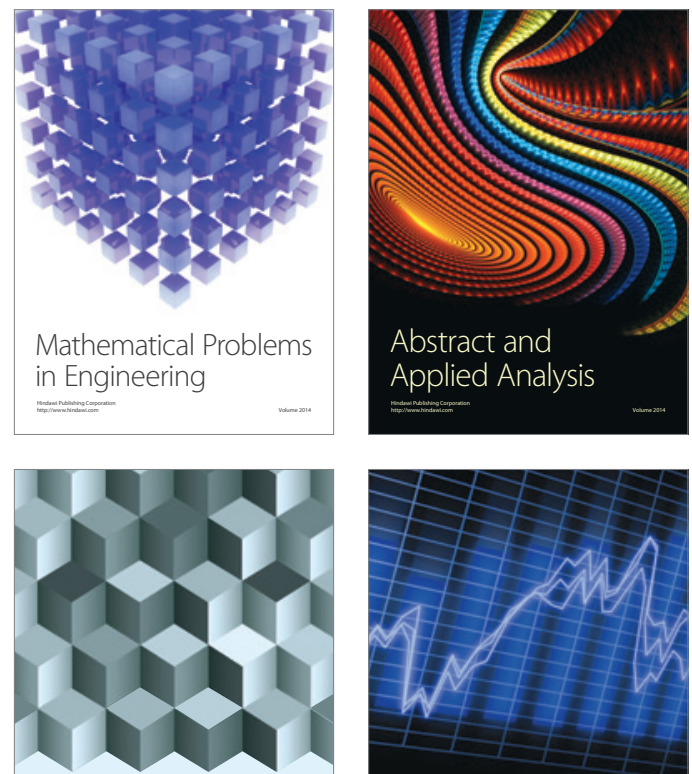

Journal of

Function Spaces

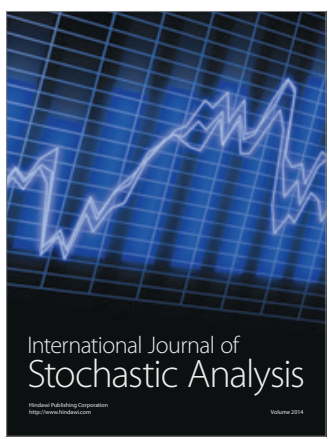

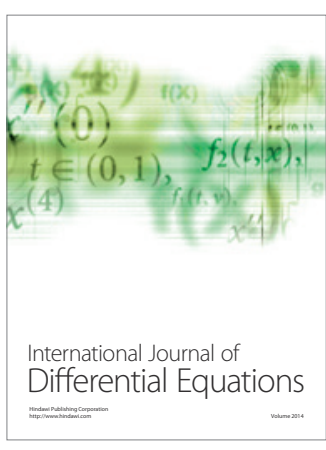
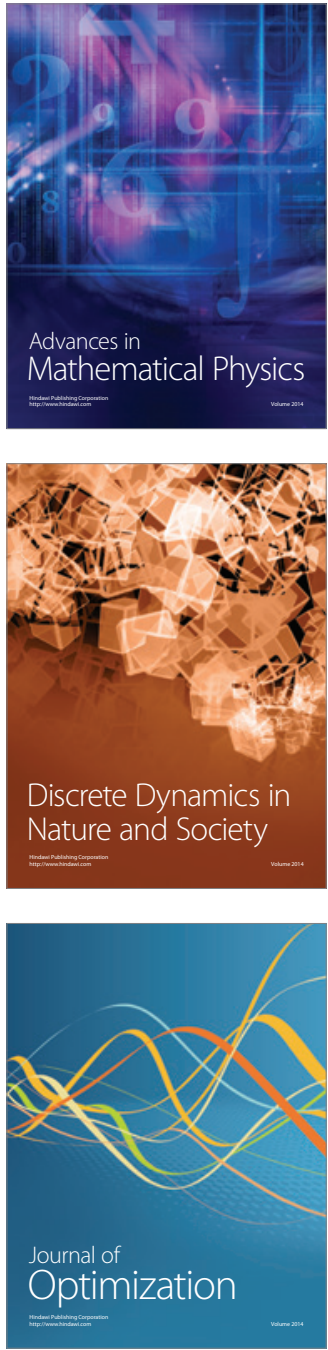